\title{
Not Only a Postdoc: The AMS Congressional Fellowship in Mid- and Late-Career
}

\section{Rachel Levy}

People often think of the AMS Congressional Fellowship as a postdoctoral opportunity. Yet only half of the 30 Congressional Fellows in my cohort were right out of their PhDs. Some were early in their career trajectories while others were making a career transition, were on a sabbatical, or were in retirement. I was almost the most senior in my group.

The opportunity to form a close, multiage and multidiscipline cohort was part of what I was seeking, and we went through a lot together. We were the first cohort to start during the pandemic. We also worked during a transition in presidential party and control of the Senate, and experienced the trauma of the January 6 insurrection. On January 6, 2021, some Fellows were on site on the Hill and some were not, but all of us were concerned for our colleagues and our nation. This experience and our many more positive ones have helped to form lifelong bonds that I look forward to maintaining.

When you become an AMS Congressional Fellow, you join an incredible alumni network of PhDs in a variety of fields and professions. My cohort loved helping the incoming Fellows this year during their placement process through lunches, resume review, online socials, and oneon-one phone calls. At the beginning of my fellowship, the former AMS Fellows got together online to welcome me, and I look forward to being part of this group going forward. The cohort of Congressional Fellows sponsored by a variety of professional societies pop up in all kinds of

Rachel Levy is the executive director of Data Science Academy and a professor of mathematics at North Carolina State University. Her email address is rache1.1evy@gmai1. com.

For permission to reprint this article, please contact: reprint-permission aams.org.

DOI: https://dx.doi.org/10.1090/noti2395 contexts-and you are connected to many other Fellows and Hill staffers forever more. In addition, you become connected with the larger cohort of Executive Branch Fellows which grows by hundreds each year who serve across government and many other sectors.

I must admit that I had always fantasized about participating in an Executive Branch Fellowship, serving in a government agency that was familiar to me, such as the NSF, NOAA, USAID, NIH, or NIST. I should also admit that I was not the most attentive in my 8th grade civics course or my 11 th grade US history course, which are the only times I can remember learning about how the US government functions. But I was convinced to pursue the AMS Congressional Fellowship because former Fellows spoke so highly of the experience, calling it a once in a lifetime opportunity. Although most of them did not choose to stay on the Hill to work as a regular staffer in the House or Senate, they all felt the experience was transformative in their careers. I agree.

The fellowship taught me that every House and Senate office is run similarly to a small business, with its own culture and working practices. I loved learning about how to communicate in the language of Congress from my colleagues, most of whom are younger than my adult children! In these difficult times, I wanted to learn how Congress could get things done in a bipartisan way amidst so much polarization. People who have worked on the Hill for decades say it comes down to the positive relationships that have been built behind the scenes (which are often much warmer than you might see on the news), though recently they have been some of the most strained in their careers.

During my fellowship year, I worked on healthcare and education policy in the context of COVID-19. I was able to listen in on meetings with Dr. Anthony Fauci, help my office write questions for hearings on a variety of topics, 


\section{AMS COMMUNICATION}

raise issues about accessibility of testing sites and websites for people needing accommodations such as a personal assistant or screen reader, and request a Governmental Accountability Office Report on higher education accommodations during COVID-19. I was able to meet weekly for six months with an external policy group to model the cost of a proposed bill. I even helped my boss introduce a bipartisan and bicameral bill (which means it had four cosponsors-a Democrat and a Republican in each of the House and the Senate). My eighth-grade civics teacher would be so proud!

I would encourage mathematicians at all phases of their careers to consider the AMS Congressional Fellowship as an extraordinary opportunity, one for which I am grateful. The networking and skills I gained were important in my job search and serve me each day in my new position. The stipend for the fellowship may be a challenge for mid- to late-career professionals, but I recommend the experience in any case. If you are interested in the fellowship, don't hesitate to reach out to former Fellows to learn about their experiences. And don't discount yourself if, like me, you have never experienced this type of work. The fellowship provides a public policy learning experience for $\mathrm{PhD}$ mathematicians to serve Congress and for us to bring knowledge of Congress back into our world.

Information on the AMS Congressional Fellowship can be found at https://www.ams.org/programs/ams -fel1owships/ams-congressional-fel1owship.

ACKNOWLEDGMENTS. The author would like to thank Anita Benjamin and Karen Saxe for their editorial suggestions.

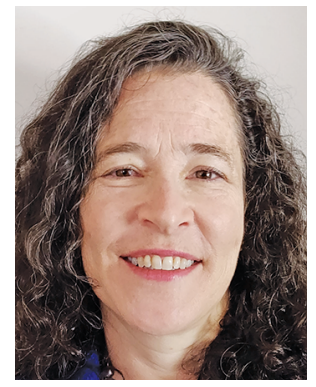

Rachel Levy

Credits

Photo of Rachel Levy is courtesy of Sam Kome.

\section{JOIN THE AMS...}

or renew your membership today

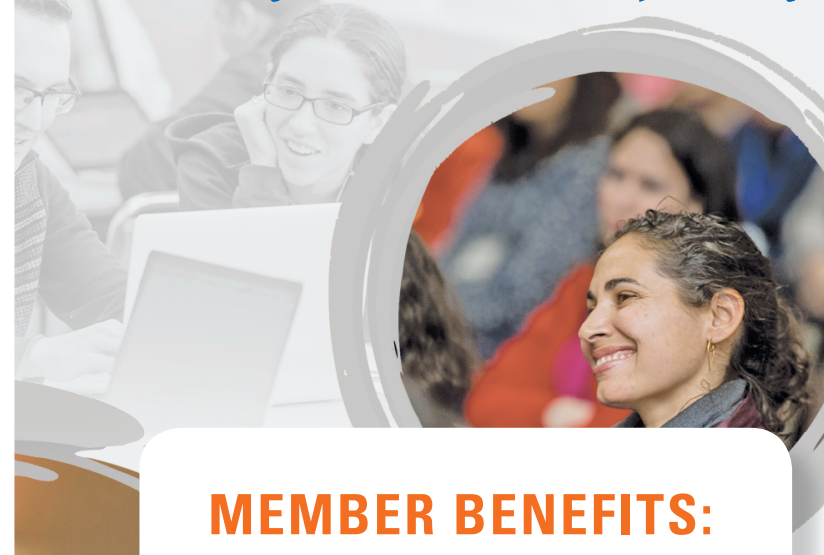

- Individual AMS members receive free standard shipping on orders delivered to addresses in the United States (including Puerto Rico) and Canada

- Discounts on AMS publications including MAA Press books

- Subscriptions to Notices and Bulletin

- Discounted registration for world-class meetings and conferences

- Access to online AMS Member Directory

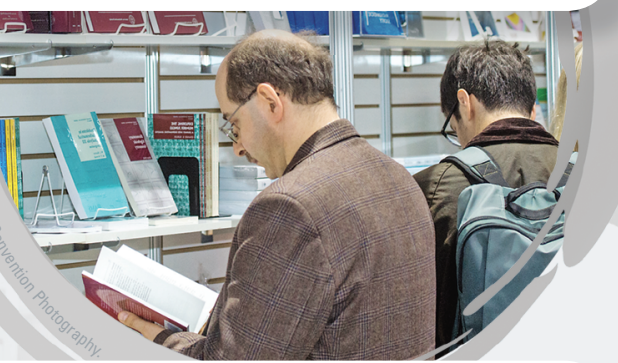

Learn more and join online at www.ams.org/membership.

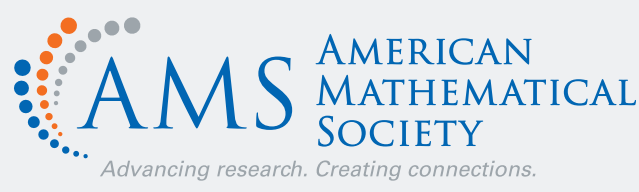

